\title{
Factors affecting employment during crisis in private businesses in Kurdistan
}

\author{
Dr. Ayoub Hasan
}

General Director of Administration and Finance, Ministry of Planning, Erbil, Kurdistan region of Iraq

\begin{abstract}
The main aim of this study is to investigate the critical factors that effecting employment during crisis in private businesses in Kurdistan. An empirical quantitative technique utilized to analyze the present research. The researcher applied a random sampling method, where all respondents had equal chances of being selected for the sample. The research was carried out at 18 private businesses in Erbil. The population of this research was approximately 341 employees, accordingly to cover the entire research population; 100 surveys were distributed but 84 forms were collected that were accomplished accurately. The results showed that the highest value was for economic factor this means that economic is strongly related to employment and has strong influence on employment during crisis in private businesses in Kurdistan.
\end{abstract}

Keywords-employment, crises, private businesses, Erbil, Kurdistan.

\section{INTRODUCTION}

Fundamental the adjustments in total employment showcase results there are substantially bigger streams of people into and out of business, unemployment and the employment drive. Understanding the determinants of these streams can reveal insight into total advancements and refine an appraisal of the level of extra limit in the employment showcase. For instance, total advancements could reflect changes in the structure of the populace or changes in the inclination of specific gatherings to take part in the employment showcase. An evaluation could be made that the potential employment supply (as estimated by the quantity of unemployment people) might be littler if the unemployment comprises of people who are more averse to be coordinated to an occupation than others, given their attributes. Interestingly, if people outside the employment constrain, for example, the insignificantly appended, show comparative conduct to the individuals who are unemployment, at that point the potential supply of employment could be bigger than something else(Drydakis, 2015).
As opposed to other sociologies, the utilization of subjective prosperity to gauge utility has been new in financial aspects. The writing in subjective prosperity begins from (Pavlínek, 2015). He recognizes that the levels of detailed subjective prosperity are not expanding as a nation creates. In customary financial hypothesis, utility is estimated by person's decisions and inclinations that were taken under reasonable suppositions (Lins, et al., 2017). This infers utility is estimated as far as utilization. An individual is relied upon to pick sound between various products keeping in mind the end goal to locate the ideal decision that will augment their own levels of utility.

Employment advertise measurements aside, the circumstance is dire to the point that it undermines a critical establishment of the current economic and social model. Financial and social arrangements over the world are still supported by confidence in the likelihood of accomplishing nonstop economic and social advance. Practically all nations are focused on the objective of accomplishing high rates of economic development and rising expectations for everyday comforts for all.

In developing countries, the crisis has brought about a slower rate of economic development in light of exchange and speculation linkages with the industrialized nations. It has likewise made the future prospects for development more unverifiable in light of the fact that entrance to budgetary markets, outside direct speculation and authority improvement help are presently more restricted than before the crisis. While less disturbing than an inside and out economic constriction, a log jam in development bothers the officially significant issues of underemployment and destitution that most developing countries confront.

Indeed, even before the beginning of the crisis, numerous developing countries, including quickly growing ones, for example, China and India, were confronting declining rates of occupation creation in the advanced area. The business substance of development in the cutting edge division, particularly in assembling, had been declining because of the expanding capital force of new ventures. Accordingly, a developing offer of new employment creation has been in the low profitability casual section of the economy. In the 
meantime, there has been an expansion in shaky types of employment in the advanced part. Youth in developing countries have been confronting expanding trouble in finding average employment in the cutting edge formal portion of the economy, and a developing extent of youngsters have needed to make due with substandard employments in the provincial and casual economy. From this point of view, any determination of the worldwide economic crisis would additionally debilitate the employment prospects of youth in developing countries (Hughes-Morley, et al., 2015).

Alongside the crisis a rising number of studies shows up on youth' employment frailty and vulnerability however in altogether different strands of the writing and confined in various wordings, for example, drawback, unemployment scarring, employment advertise dualism, social stratification, neediness, life course chances, social avoidance and (intergenerational) imbalance. The national employment markets perform contrastingly in financial and social terms and speak to rather particular methods for administration and social models (De Goeij, et al., 2015). The part of administration as for employer stability relates to the effect of controls, open strategies and private division courses of action on employment advertise security results as talked about in the welfare state and mechanical relations writing.

\section{LITERATURE REVIEW}

The worldwide economic and financial crisis activated sharp yield compressions in every single industrialized economy in 2008 without precedent for the post-Second World War time. Other than the immediate effects of this compression in created economies, resulting decreases in cross-outskirt exchange and the increasing expense of fund had genuine negative consequences for rising and creating economies. Specifically, as organizations slice generation because of lower total request, laborers were shed in expansive numbers, forcefully expanding unemployment around the world. In the vicinity of 2007 and the finish of 2009 there was a remarkable increment in the numbers unemployment (Oganjan, et al., 2017). This detailed increment in unemployment in all likelihood thinks little of the genuine profundity of the issue, since employment misfortune figures depend on official employment insights, which in numerous developing countries just covers employment in the formal economy, for the most part in urban regions. Past occupation misfortunes, the nature of employment likewise disintegrated in both created and developing countries. Over the globe, numerous specialists who did not lose their occupations were compelled to acknowledge decreased employment hours and lower wages and advantages. The circumstance is as a rule additionally irritated by gravity measures in most created economies (Schnurr \& Allen, 2015). The Great Recession has therefore made an employments crisis. The expanded activity frailty because of the retreat has brought about maintained and crushing effects on people, families, families and their groups. Groups are influenced when producing occupations vanish because of plant terminations or employment force downsizings, or when youngsters move to different urban communities and towns looking for better openings for employment. Such employment misfortunes since 2008 have pushed endless families into budgetary and economic hardship, bringing about the loss of homes to abandonment and increments in destitution, obligation and insolvency, particularly in the United States and other propelled economies(Smith, et al., 2015). Since employment is personally identified with a few measurements of individual prosperity, employment misfortunes and compounding employment and economic frailty have likewise been related with expanded weakness, mental hardship and family disintegration(Curran \& Baker, 2016). The subsidence has likewise influenced different social and financial gatherings in altogether different ways. When all is said in done, ladies have been lopsidedly unfavorably influenced, yet in a few economies, the unfriendly effects on men have been more extreme than on ladies. In different economies, less talented laborers, youth, more seasoned people and vagrant specialists have endured as far as lost employments, advantages and profit. These impacts have likewise differed crosswise over and inside districts and nations(Bedwell, et al 2015).

\subsection{Factors affecting employment during crisis}

The employment has differentiated affected working conditions developing countries, and in Norway, as is reflected in the national commitments arranged for this report. Malta and Poland report being scarcely influenced by the employment. Different nations report that the employment has had significant impacts, frequently with an exceptional effect on unemployment, youth unemployment and long haul unemployment(Manskow, et al 2015). There is likewise some variety between nations with respect to the span of the employment. Some national commitments take note of that the effect of the employment on business and working conditions appeared to fall behind the financial employment. In any case, the employment significantly affected the work market of all Member States in 2009 and 2010. The tentative recuperation of work in 2011 finished with the arrival of low or negative financial development rates. In the accompanying segments, this advancing 
employment is considered in connection to working conditions in the developing countries(Gandhi-Lee, et al 2017). Transitory business (subordinate work of restricted length) can be seen for the most part as the blend of hiring organization work and occupations with settled term contracts. There are expansive contrasts between Member States in the rate of these two sorts inside the gathering of brief workers because of nation particular arrangements and traditions. They are in this way talked about here as one wonder. The investigation of authoritative employment is still to a great extent at a formative stage(Lacour \& Bourdin, 2015). Thusly, Brewster, et al., (2014) together with different specialistscalls for more observational examinations in hierarchical employment. We have already settled that authoritative employment is a sudden, surprising and spontaneous occasion that effects affects the association's main concern(Donohue, et al., 2017). Impression administration may likewise be characterized as the practices utilized to make and ensure mental self-views and impressions and, particularly, to impact how one is seen by noteworthy others(Alkhamis \& Miraj, 2018). A refusal methodology is utilized when senior administration essentially denies submitting the demonstration. Senior chiefs may likewise utilize avoidance of duty where the administration guarantees an absence of control over the circumstance. Thus, senior directors utilize lessening the obnoxiousness of the occasion, that is, they create positive emotions among partners to balance negative sentiments associated with the wrongful demonstration(Li,2015).

\subsubsection{Political factor}

A strong share of market analysts is currently of the sentiment that, even in an entrepreneur framework, full employment might be secured by an administration spending program, gave there is in presence sufficient arrangement to utilize all current employment control, and gave satisfactory supplies of vital remote crude materials might be acquired in return for sends out. In the event that the legislature embraces open speculation (e.g. constructs schools, healing facilities, and interstates) or finances mass utilization (by family stipends, diminishment of circuitous tax assessment, or appropriations to keep down the costs of necessities), and assuming, besides, this use is financed by obtaining and not by tax collection (which could influence antagonistically private speculation and utilization), the successful interest for merchandise and ventures might be expanded up to a point where full employment is accomplished. Such government use expands business, be it noted, straightforwardly as well as in a roundabout way too, since the higher earnings caused by it result in an auxiliary increment popular for buyer and venture products(Chen, et al 2017).

Specifically, for a cross segment of nations, barring nonmajority rule governments, demonstrates that more noteworthy polarization brings about obstructions to venture which are relieved by the level of political soundness. Here, we center around employment showcase organizations and demonstrate that political shakiness can clarify why governments frequently take wasteful choices as for employment directions, or are hesitant to transform them even in a setting of high unemployment(Cadden \& Arnett, 2015). This has a few expenses since it decreases the assets accessible for open great arrangement, redistribution, and social protection. Second, numerous investigations depend on information with high crosscountry inconstancy in connection to the implementation of majority rule organizations, to develop measures of political insecurity in view of transformations, overthrows, and deaths, which catch wonders, for example, xenophobia, hostile to Semitism, social agitation, and ultra-patriotism. We demonstrate that political precariousness - estimated as far as political turnover and polarization - can affect financial execution even inside nations portrayed by vote based foundations (Ellenkamp, et al., 2016).

The absence of assets and political personality that might be credited to problematic specialists is probably going to be exacerbated by the state of unemployment, with critical outcomes on political engagement. A current survey of the writing presents expected political states of mind and practices of unemployment: high abstention levels in races; high extents of outrageous right or left-wing voting; a low level of trust in political establishments(Saridakis, et al., 2014). Therefore, we would expect a general low level of political cooperation of the unemployment when contrasted with consistently utilized individuals; yet additionally in contrast with shaky specialists who, disregarding their condition, are still preferable off over the individuals who are completely rejected from the employment advertise in such manner. In any case, the impact of unemployment on political dispositions and practices has been shown to be dependent upon the financial status(Boeckmann, et al., 2014). Since the effect of unemployment isn't the same crosswise over social gatherings, we should put unemployment in a more extensive life setting so as to examine its effect on political cooperation. Along these lines in our examination we consider the effect of political attributes when testing the impact of the employment status on political interest.

One of the points of confinement of these examinations is that it is hard to learn whether routinely utilized individuals 
are not the same as unemployment individuals from the start as expressed by (Delfabbro, et al., 2017). One approach to meet this feedback is to take a gander at unstable laborers, notwithstanding these two gatherings, as they can be viewed as standing some place in the middle of the other two gatherings. In such manner, Sima, et al., (2015) found no impact of brief employment on political investment. Also, different examinations have scrutinized the course of the connection amongst business and political interest and additionally the very presence of the relationship. Sockalingam, et al., (2015), for instance, have discovered that political interest can clarify dispositions and practices in the working environment, turning around the connection between the two factors. To comprehend this perplex, Adman (2008) has tried the impact of employment on political interest with board information. The impact found in cross-sectional investigations does not hold when one considers the fleeting requesting of occasions (first being engaged with a particular working environment setting, at that point partaking politically).

\subsubsection{Education}

A high instructive level expands employment advertise inclusion and allows people to get higher salary. Nair \&Farid, (2016) exhibited by an econometric model this wage increment as instruction increments. As per insights gave by a few universal associations (World Bank, Eurostat), an abnormal state of education expands business. This is clarified by the way that a superior arranged individual will have higher efficiency and will adjust all the more effortlessly to the progressions and requests of globalization and improvement of new innovations, having the capacity to gain all the more effectively new abilities. Very much arranged talented employmentforce builds employment productivity in any field, and expanded employment effectiveness underpins financial development and improvement. The human capital model does not accept that the employment units are homogenous. Then again, non-homogenous employment units frame one of the basic components of their examination. They theorized that people vary as far as the sort and levels of abilities they have(Yeager \& Wisniewski, 2017). Additionally, their significant commitment lies in giving a sensible clarification to the differential aptitudes and related wage differentials. As indicated by this model, differential aptitudes are specifically identified with the differential levels of education achieved by the people. A d the levels of instruction achieved specifically compare to the sums put resources into education. Business people were unequivocal in their clarification in regards to the aptitude teaching part of instruction. According to Hughes-Morley, et al., (2015) contended that instruction creates intellectual abilities which enhance the effectiveness and in this manner the profitability of people, i.e. better taught people contributes more to the national pay. In view of the negligible profitability hypothesis of dissemination, they contended, and defended the higher financial prizes to the informed than to the less or uneducated.

In the course of recent years the developing countries economy has been developing and its structure evolving. In any case, the greater parts of the occupations which have been made as of late have not been in the divisions where development has been biggest, for example, mining and development, but instead in different kinds of administrations(Alkhamis \& Miraj, 2018). In parallel to these adjustments in labor request there has been a huge increment in school enrolment, especially at optional school level, and with this a fall in the extent of the employment constrain with just essential education and a relative increment in those with post-auxiliary instruction. Notwithstanding the expansion in the quantities of those with more instruction there exists the discernment that the education framework isn't addressing the necessities of the evolving economy(Bedwell, et al 2015). This paper explores this issue utilizing quantitative information drawn from employment market and firm reviews, and a progression of meetings attempted with business supervisors, industry agents and government authorities. The nature of the Developing countries educational system is poor contrasted with different nations inside the district yet in spite of this, all things considered, organizations in Zambia are probably not going to report that aptitudes are a requirement for them and are probably not going to take part in their own preparation(Cadden \& Arnett, 2015). Aptitudes preparing necessities are heterogeneous crosswise over areas and the profits to education vary essentially between parts. Instruction past auxiliary school is related with significant premiums in people in general area and in private parts, for example, mining and assembling. In the long haul any endeavor to enhance abilities inside the Developing countries employment market should handle the nature of essential and optional school education. In the shorter-term, the post-auxiliary instruction framework needs to better fit the understudies which are rising up out of the educational system and open preparing establishments need to team up additional with the private part to meet their particular needs(Chen, et al 2017).

This relationship is seen in the investigation of the markers on personal satisfaction. Personal satisfaction is gotten in various examinations and investigation that depend on a 
progression of markers. A few investigations utilize the marker of life fulfillment, which is exceptionally subjective; however which is impacted by numerous components, including education, pay, employment or unemployment(Curran \& Baker, 2016). Unemployment influences the personal satisfaction, not just by the loss of wage that people and families need to confront, yet in addition through the mental costs they produce (particularly long haul unemployment), with suggestions on person's life fulfillment. Numerous examinations demonstrate the significance of the investigation of life fulfillment and different variables, other than the wage got. Individuals' definitive target is bliss and the cash is just a single of numerous approaches to build general life fulfillment(De Goeij, et al., 2015). In this manner, personal satisfaction can be caught by considering numerous components, for example, employment fulfillment, employment-family adjust, time for diversion, wellbeing, security, living conditions, education, foundation, confide in establishments, and so forth.. For instance, the absence of harmony amongst employment and family causes pressure, low productivity at employment, disappointment with life, so an abatement in personal satisfaction. Then again, (Donohue, et al., 2017) think about that a harmony amongst employment and family positively affects personal satisfaction, more grounded than the pessimistic effect that would have happened without this adjust.

\subsubsection{Social}

The viability and profitability of an association rely upon the improvement and supporting of its employment force. It is neither conceivable nor down to earth to build the efficiency of an association without considering the ideal abusing the faculty capacities(Donohue, et al., 2017). In this way, powerful administration and use of its fitting techniques and strategies have been accepted impressive significance(Ellenkamp, et al., 2016). It is generally said that "an upbeat laborer is a compelling one" and a cheerful specialist ought to be happy with his activity. The significance of employment fulfillment comes about because of the way that the vast majority spends about portion of their waking hours at employment(HughesMorley, et al., 2015). The idea of employment fulfillment has various definitions. From one perspective, it is the same as demeanor, with employment fulfillment as the aggregate of the feelings concerning the activity directed. On the off chance that the laborer sees that her/his esteems are acknowledged inside the activity, she/he will have an uplifting disposition towards her/his activity and obtain employment fulfillment(Lacour \& Bourdin, 2015). Hierarchical advancement is a strategy through which authoritative capacity is enhanced and is a long haul program which impacts the difference in employee's conduct and disposition. Occupation fulfillment is characterized as an individual's understanding towards her/his activity and calling $(\mathrm{Li}, 2015)$.

There is a developing enthusiasm for hypothetical models of associate impacts and informal communities. Nonetheless, there are not very many papers that expressly think about the association between the social and the geological space. (Lins, et al., 2017), is the main paper that has the two perspectives yet the concentration is very surprising since the paper predominantly clarifies the contrasts amongst blacks and whites as far as employment showcase outcomes. (Manskow, et al 2015), is obviously an original reference while talking about social inclinations and area. Shelling's model demonstrates that, even a mellow inclination for cooperating with individuals from a similar group can prompt huge contrasts as far as area choice. For sure, his outcomes recommend that aggregate isolation holds on regardless of whether a large portion of the populace is tolerant about heterogeneous neighborhood composition. The model is altogether different from models a la Schelling since we center around powerless and solid ties and their effect on employment showcase results.

\subsubsection{Legal}

Businesses may not pay unequal wages to men and ladies who perform occupations that require significantly square with aptitude, exertion and obligation, and that are performed under comparable working conditions inside a similar foundation(Oganjan, et al., 2017). Every one of these variables is compressed underneath: Skill- Measured by components, for example, the experience, capacity, instruction, and preparing required playing out the activity. The key issue is the thing that aptitudes are required for the activity, not what abilities the individual workers may have. For instance, two accounting occupations could be viewed as equivalent under the EPA regardless of whether one of the jobholders has a graduate degree in material science, since that degree would not be required for the activity(Pavlínek, 2015). Exertion- The measure of physical or mental effort expected to play out the activity. For instance, assume that men and ladies work one next to the other on a line gathering machine parts. The individual toward the finish of the line should likewise lift the amassed item as he or she finishes the work and place it on a board. That activity requires more exertion than the other sequential construction system occupations if the additional exertion of lifting the amassed item off the line is considerable and is a general piece of the activity(Saridakis, et al., 2014). Therefore, it would not be an infringement to 
pay that individual all the more, paying little heed to whether the activity is held by a man or a lady. Responsibility - The level of responsibility required in playing out the activity. For instance, a salesman who is designated the obligation of deciding if to acknowledge clients' close to home checks have more duty than other sales representatives. Then again, a minor distinction in obligation, for example, turning out the lights toward the day's end, would not legitimize a compensation differential(Schnurr \& Allen, 2015). Working ConditionsThis incorporates two elements: (1) physical environment like temperature, exhaust, and ventilation; and (2) perils. Foundation- The restriction against pay separation under the EPA applies just to occupations inside a foundation. A foundation is an unmistakable physical place of business as opposed to a whole business or endeavor comprising of a few spots of business. In any case, in a few conditions, physically isolate spots of business ought to be dealt with as one foundation. For instance, if a focal managerial unit contracts representative, set their pay, and relegates them to work areas, the different work destinations can be thought about piece of one foundation(Smith, et al., 2015).

Worker determination is the procedure by which the most effective and qualified representative is chosen to possess the post far from nepotism and preference, nepotism. The choice of representatives relying upon their capabilities and encounters that suit their desires isn't the end for the administrations however the execution of these workers should be followed up as they might be prepared and engaged to achieve a level in which they can take choices identifying with their occupations without refereeing to their supervisors(Yeager \& Wisniewski, 2017). By choosing right contender for the required activity, associations will likewise spare time and cash.Legitimate screening of applicants happens amid determination method. All the potential applicants who apply for the given occupation are tried. While it has dependably had the ability to frame a key piece of the way toward overseeing and driving individuals as a standard piece of hierarchical life, it is recommended choice has turned out to be always critical as associations progressively view their workforce as a wellspring of upper hand(Alkhamis \& Miraj, 2018). (Boeckmann, et al., 2014), expressed that the dependability of a representative choice instrument, for example, a test, is the degree to which the instrument is a reliable measure of something. An insight test is said to be solid, if a similar individual's scores don't shift enormously when the test is taken a few times. The higher the unwavering quality, the more certainty can be put in the estimation strategy. As a rule, the instrument is more solid in the event that it is
longer(Chen, et al 2017). The instrument utilized should likewise be inside steady to be viewed as solid, which a decent indicator of achievement for the activity execution is being referred to. It ought to be noticed that the paradigm used to foresee execution or achievement is an intermediary of real execution. Since great job execution is normally a mix of numerous variables (nature of work, amount of work, and so forth.) a basis, for example, a supervisory rating is an intermediary for the genuine measure, work achievement or execution(Curran \& Baker, 2016).

One conceivable approach reaction to these worries is changing the definitions presently being used in work law. Specifically, more prominent utilize may be made of the lawful idea of 'laborer', which is more extensive than that of 'representative'(Drydakis, 2015). Some independently employed people who are not in business all alone record and who contract to give their own administrations to another would go under the meaning of 'specialist'. These 'needy independently employed' are among the chief gatherings whose business status is as of now in question(Ellenkamp, et al., 2016).

\subsubsection{Economic}

Globalization and Internationalization are terms which wound up regular in numerous economic businesses(Gandhi-Lee, et al 2017). When we take a gander at the car business, the electronic business, the interchanges business, the garments business, nourishment industry or even the drug store industry, just to specify a couple of cases, are spread everywhere throughout the world and the plans of action of numerous organizations acting in one of these enterprises frequently truly are globalized or if nothing else multi-national. Also, this procedure even has begun a few decades prior. This is the motivation behind why the significance of multi-national-organizations expanded quickly in this brief timeframe(Lacour \& Bourdin, 2015). Miniaturized scale and also large scale economic components impact the financial exercises of such complex organization systems. The impacting components can be seen from the inward perspective of an organization, characterized as the purported small scale financial variables and from the outside perspective, the supposed large scale economic elements(Ellenkamp, et al., 2016). Concentrating on the external perspective of an organization and its exercises, following circumstance ends up self-evident. The more perplexing such an organization arrange, the more vital the outer impact factors move toward becoming.

Microeconomic elements impact the aggregate bartering energy of a specific manager or association through the impacts of focused conditions on a firm. The more 
prominent the market energy of a firm (i.e., the less rivalry it faces in the business sectors in which it contends) the more noteworthy will be its benefits. With more prominent benefits, there are more assets for the gatherings to isolate in view of their relative power( $\mathrm{Li}, 2015)$. A company's market control is influenced by the level of household and universal rivalry it faces. As to add up to bartering force, work and administration have regular premiums; the two sides favor that the firm have showcase control. (This is valid if different elements are held steady, particularly factors that influence the relative energy of work and administration.)(Manskow, et al 2015).

Economic development requires factor reallocation crosswise over firms and ceaseless substitution of advances. Work advertise establishments impact financial dynamism by their effect on the supply of a key factor, gifted specialists to new and growing firms, and the shedding of laborers from declining and fizzling firms(Oganjan, et al., 2017). Development favoring work advertise establishments incorporate versatile benefits designs and other occupation residency rights, medical coverage loosened to the present manager, individualized wage-setting, and open salary protection frameworks that energize portability and hazard taking(Saridakis, et al., 2014). Economic has hence significant ramifications for the work advertise. Specifically, economic will change both the amount and nature of work requested. In reality, a consistently expanding piece of work can be performed naturally, with constrained or no human intercession. This marvel isn't new: amid industrialization, basically straightforward, tedious undertakings were robotized. What contrasts now is that less much of the time performed and more mind boggling undertakings are likewise progressively subject to computerization, e.g. organization(Smith, et al., 2015). This lessens the interest for low-gifted yet specifically mediumtalented and even the lower levels of high-gifted cubicle laborers that right now play out these undertakings. Thusly, the rest of the specialists require unique, frequently higher, more innovative and specialized abilities to configuration keep up and work with the new applications. Economic additionally enables laborers to do their work all the more effectively. Specifically, in late decades, economic has essentially changed the way individuals work, with, for instance, more help from online interchanges and data sharing and also mechanical help for data preparing, which on a fundamental level means less individuals are expected to play out a similar errand, yet in addition that the aptitudes requested of specialists may change, i.e. economic

fundamentally assumes control straightforward
undertakings, in this way specialists must have higher capabilities. Moreover, economic additionally makes new types of business. For example, new procedures, for example, huge information examination, added substance printing, virtual reality and the Internet of things consider the advancement of new, more intricate and modern items and administrations(Cadden \& Arnett, 2015). The new occupations to create and keep up these items/benefits regularly require higher aptitudes, while the use of the advances can likewise make more administration situated low-gifted employments. The progress towards the more advanced work market can thusly be encouraged by computerized arrangements, for example, elearning(Saridakis, et al., 2014). Large scale variable that our examination investigates is the quantity of web clients. Ideas, for example, "web strengthening" has been around for quite a while. Its part in advancing and supporting private companies is investigated by(Curran \& Baker, 2016) as they feature the business advancement administrations gave by the web. These administrations incorporate, however are not restricted to, preparing, counseling, advising and organizing. One of the best difficulties looked by potential business people is an absence of assets. Absence of information with respect to promoting, administration, and business new companies is another issue. Web based information is important in such manner. It additionally assumes a vital part in leading statistical surveying and finding out about existing rivalry(Ellenkamp, et al., 2016). New startup proprietors utilize the web to take advantage of a worldwide system of business visionaries and we absolutely anticipate that it will be an extraordinary supporter of simplicity of business. In a paper by the National Bureau of Economic Research, serial business people or business visionaries who had prevailing in the past were seen to probably prevail than those starting a business out of the blue. More experience and ability appears to trump different intangibles, for example, luckiness. Expertise may be characterized as capacity to recognize markets and strategize to the benefit of the firm. This kind of learning is not quite the same as the instruction got at a school or a school. Our investigation controls for intangibles, for example, business person's expertise, outlook and foundation(Lacour \& Bourdin, 2015).

\section{METHODOLOGY}

\subsection{Conceptual framework}

3.1.1 Research method 


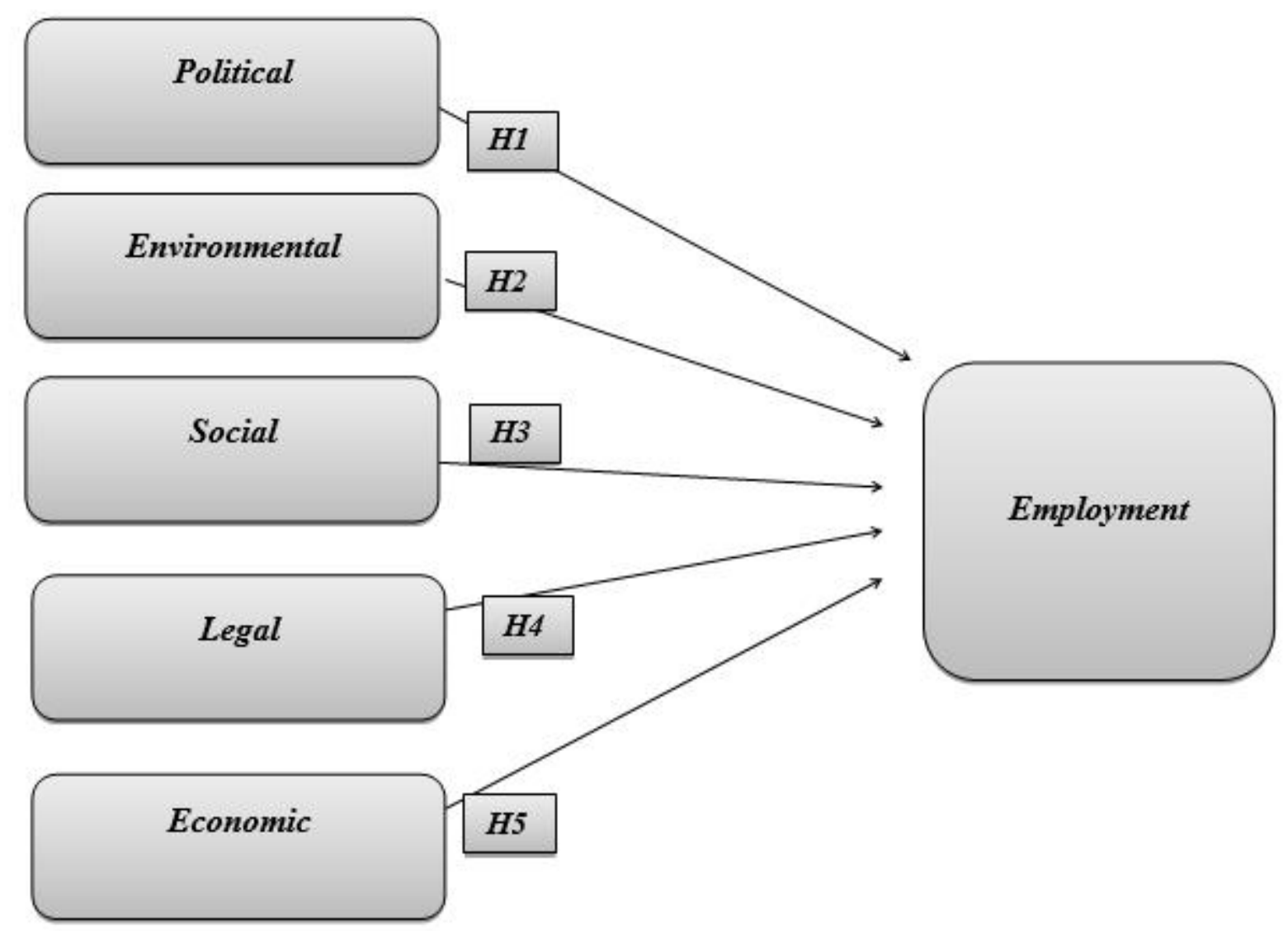

\section{Research hypotheses}

First research hypothesis: Political factor has a positive and significant impact on employment during crisis in private businesses in Kurdistan.

Second research hypothesis: Environmental factor has a positive and significant impact on employment during crisis in private businesses in Kurdistan.

First research hypothesis: Social factor has a positive and significant impact on employment during crisis in private businesses in Kurdistan.

First research hypothesis: Legal factor has a positive and significant impact on employment during crisis in private businesses in Kurdistan.

First research hypothesis: Economic factor has a positive and significant impact on employment during crisis in private businesses in Kurdistan.

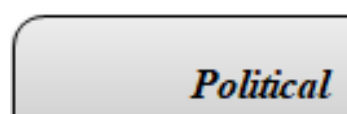

Political

\subsection{Design of the Study}

The aim of this study is to analyze the impact of factors affecting employment during crisis in private businesses in Kurdistan. An empirical quantitative technique utilized to analyze the present research.

\subsection{Sample Size and sampling method}

The researcher applied a random sampling method, where all respondents had equal chances of being selected for the sample. The research was carried out at 18 private businesses in Erbil. The population of this research was approximately 341 employees, accordingly to cover the entire research population; 100 surveys were distributed but 84 forms were collected that were accomplished accurately.

\section{RESULTS AND ANALYSIS}

4.1 Testing first hypothesis

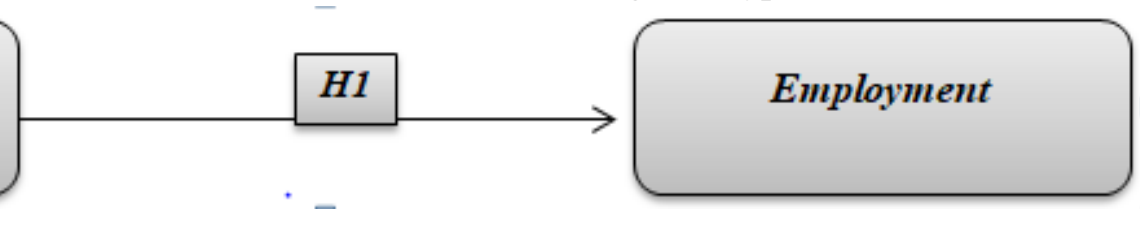




\begin{tabular}{ccc}
\hline Factor & Cronbach's Alpha & Number of questions \\
\hline Political & .734 & 9
\end{tabular}

Table (1) presents the reliability tests for first independent factor, it was foundthat the value of Cronbach's Alpha for 9 items was found to be. 734 which is more than 0.6 indicated that 9 items used to measure political factor that affect employment during crisis were reliable for this research.

Table.2: Correlations analysis

\begin{tabular}{ccc}
\hline Factors & Pearson & Political \\
\hline & Pearson Sig.(2-tailed) & $.709 * *$ \\
Employment & $\mathrm{N}$ & .000 \\
& & 84
\end{tabular}

Table (2) demonstrates the correlation analysis between political as independent factors and employment as dependent factor. The value of Pearson correlation between political factor and employment was .709** this indicated that there is a significant correlation between political factor and employment during crisis in private businesses in Kurdistan.

Table.3: Coefficients

\begin{tabular}{|c|c|c|c|c|c|}
\hline \multirow[t]{2}{*}{ Model } & \multicolumn{2}{|c|}{$\begin{array}{c}\text { Unstandardized } \\
\text { Coefficients }\end{array}$} & \multirow{2}{*}{$\begin{array}{c}\text { Standardized } \\
\text { Coefficients }\end{array}$} & \multirow[t]{2}{*}{$\mathrm{t}$} & \multirow[t]{2}{*}{ Sig. } \\
\hline & B & Std. Error & & & \\
\hline (Constant) & .114 & .141 & & .968 & .000 \\
\hline Political & .511 & .142 & .519 & .897 & .000 \\
\hline
\end{tabular}

a. Dependent Variable: Employment

Table (3) demonstrates the coefficients test for this study. The findings revealed that the $B$ value of for political factor $=.511>$ 0.01 , which indicated that there is a positive and significant impact of political on and employment during crisis in private businesses in Kurdistan.

\subsection{Testing second hypothesis}

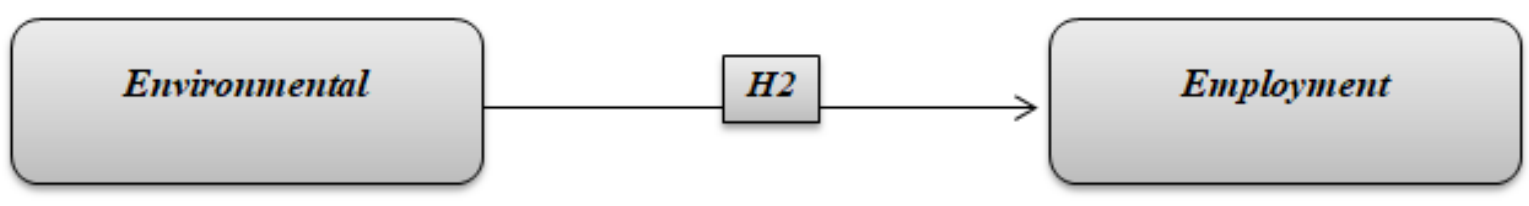

Table.4: Reliability Statistics

\begin{tabular}{ccc}
\hline Factor & Cronbach's Alpha & Number of questions \\
\hline Environmental & .712 & 8 \\
\hline
\end{tabular}

Table (4) presents the reliability tests for second independent factor, it was found that the value of Cronbach's Alpha for 8 items was found to be. 712 which is more than 0.6 indicated that 8 items used to measure environmental factor that affect employment during crisis were reliable for this research.

Table.5: Correlations analysis

\begin{tabular}{ccc}
\hline Factors & Pearson & Environmental \\
\hline & Pearson Sig.(2-tailed) & $.612^{* *}$ \\
Employment & $\mathrm{N}$ & .000 \\
& & 84 \\
\hline
\end{tabular}


Table (5) demonstrates the correlation analysis between environmental as independent factors and employment as dependent factor. The value of Pearson correlation between environmental factor and employment was .612** this indicated that there is a significant correlation between environmental factor and employment during crisis in private businesses in Kurdistan.

Table.6: Coefficients

\begin{tabular}{|c|c|c|c|c|c|}
\hline \multirow[t]{2}{*}{ Model } & \multicolumn{2}{|c|}{$\begin{array}{c}\text { Unstandardized } \\
\text { Coefficients }\end{array}$} & \multirow{2}{*}{$\begin{array}{c}\begin{array}{c}\text { Standardized } \\
\text { Coefficients }\end{array} \\
\text { Beta }\end{array}$} & \multirow[t]{2}{*}{$\mathrm{t}$} & \multirow[t]{2}{*}{ Sig. } \\
\hline & B & Std. Error & & & \\
\hline (Constant) & .102 & .132 & & .902 & .000 \\
\hline environmental & .614 & .174 & .617 & .902 & .000 \\
\hline
\end{tabular}

a. Dependent Variable: Employment

Table (6) demonstrates the coefficients test for this study. The findings revealed that the $B$ value of for environmental factor $=$ $.614>0.01$, which indicated that there is a positive and significant impact of environmental on and employment during crisis in private businesses in Kurdistan.

\subsection{Testing third hypothesis}

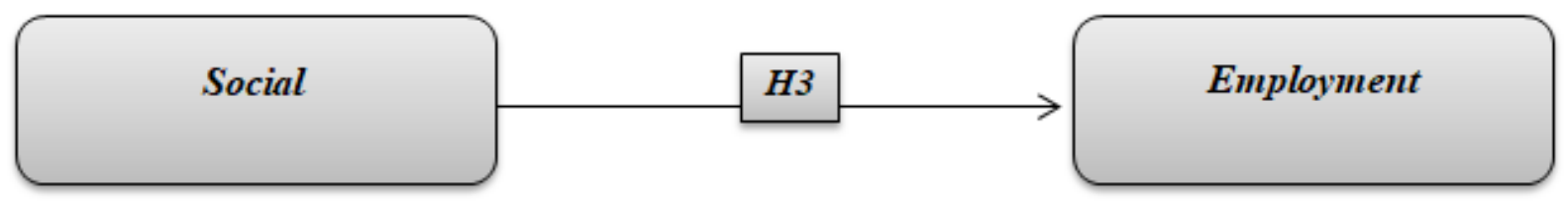

Table.7: Reliability Statistics

\begin{tabular}{ccc}
\hline Factor & Cronbach's Alpha & Number of questions \\
\hline Social & .735 & 7
\end{tabular}

Table (7) presents the reliability tests for third independent factor, it was found that the value of Cronbach's Alpha for 7 items was found to be. 735 which is more than 0.6 indicated that 7 items used to measure social factor that affect employment during crisis were reliable for this research.

Table.8: Correlations analysis

\begin{tabular}{ccc}
\hline Factors & Pearson & social \\
\hline \multirow{2}{*}{ Employment } & Pearson Sig.(2-tailed) & $.714 * *$ \\
& $\mathrm{~N}$ & .000 \\
84
\end{tabular}

Table (8) demonstrates the correlation analysis between social as independent factors and employment as dependent factor. The value of Pearson correlation between social factor and employment was $.714^{* *}$ this indicated that there is a significant correlation between social factor and employment during crisis in private businesses in Kurdistan.

\begin{tabular}{|c|c|c|c|c|c|}
\hline \multirow[t]{2}{*}{ Model } & \multicolumn{2}{|c|}{$\begin{array}{c}\text { Unstandardized } \\
\text { Coefficients }\end{array}$} & \multirow{2}{*}{$\begin{array}{c}\text { Standardized } \\
\text { Coefficients }\end{array}$} & \multirow[t]{2}{*}{$\mathrm{t}$} & \multirow[t]{2}{*}{ Sig. } \\
\hline & B & Std. Error & & & \\
\hline (Constant) & .103 & .101 & & 1.021 & .000 \\
\hline Social & .701 & .108 & .712 & .1005 & .000 \\
\hline
\end{tabular}

a. Dependent Variable: Employment

Table (9) demonstrates the coefficients test for testing the impact of social factor on employment during crisis in private businesses in Kurdistan. The findings revealed that the $B$ value of for social factor $=.701>0.01$, which indicated that there is a positive and significant impact of social on and employment during crisis in private businesses in Kurdistan. 


\subsection{Testing fourth hypothesis}

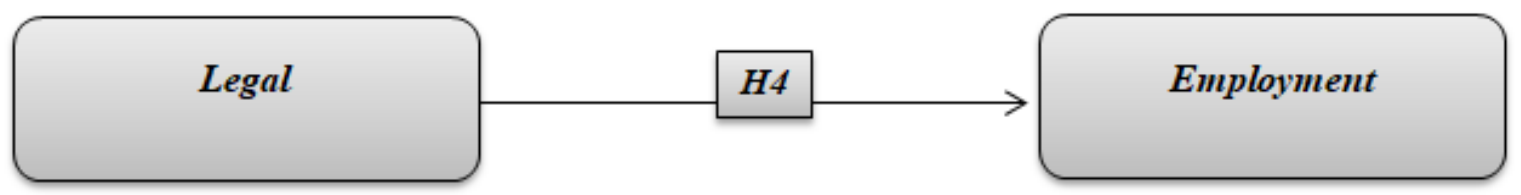

Table.10: Reliability Statistics

\begin{tabular}{ccc}
\hline Factor & Cronbach's Alpha & Number of questions \\
\hline Legal & .698 & 8 \\
\hline
\end{tabular}

Table (1) presents the reliability tests for fourth independent factor, it was found that the value of Cronbach's Alpha for 8 items was found to be. 698 which is more than 0.6 indicated that 8 items used to measure legal factor that affect employment during crisis were reliable for this research.

Table.11: Correlations analysis

\begin{tabular}{ccc}
\hline Factors & Pearson & Legal \\
\hline & Pearson Sig.(2-tailed) & $.601^{* *}$ \\
Employment & $\mathrm{N}$ & .000 \\
& & 84
\end{tabular}

Table (11) demonstrates the correlation analysis between legal as independent factors and employment as dependent factor. The value of Pearson correlation between legal factor and employment was .601** this indicated that there is a significant correlation between legal factor and employment during crisis in private businesses in Kurdistan.

Table.12: Coefficients

\begin{tabular}{|c|c|c|c|c|c|}
\hline \multirow[t]{3}{*}{ Model } & \multirow{2}{*}{\multicolumn{2}{|c|}{$\begin{array}{c}\text { Unstandardized } \\
\text { Coefficients }\end{array}$}} & \multirow{3}{*}{$\begin{array}{c}\begin{array}{c}\text { Standardized } \\
\text { Coefficients }\end{array} \\
\text { Beta }\end{array}$} & \multirow[t]{3}{*}{$\mathrm{T}$} & \multirow[t]{3}{*}{ Sig. } \\
\hline & & & & & \\
\hline & B & Std. Error & & & \\
\hline (Constant) & .089 & .074 & & .895 & .000 \\
\hline Legal & .639 & .108 & .644 & .847 & .000 \\
\hline
\end{tabular}

a. Dependent Variable: Employment

Table (12) demonstrates the coefficients test for testing the impact of social factor on employment during crisis in private businesses in Kurdistan. The findings revealed that the $B$ value of for legal factor $=.639>0.01$, which indicated that there is a positive and significant impact of legal on and employment during crisis in private businesses in Kurdistan.

\subsection{Testing fifth hypothesis}

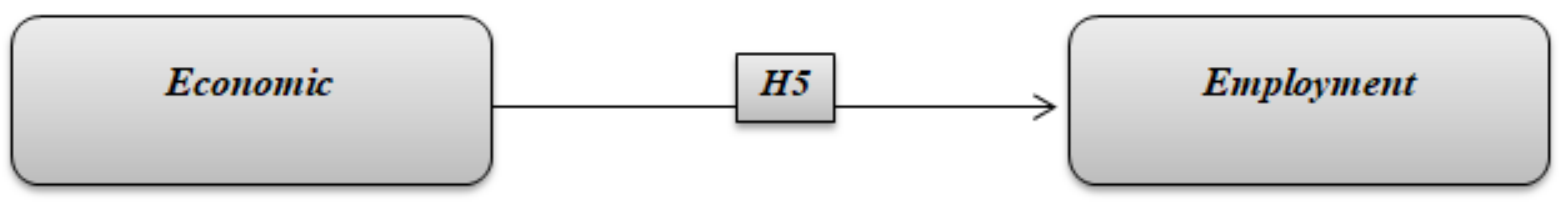

Table.13: Reliability Statistics

\begin{tabular}{ccc}
\hline Factor & Cronbach's Alpha & Number of questions \\
\hline Economic & .812 & 9 \\
\hline
\end{tabular}

Table (13) presents the reliability tests for fifth independent factor, it was found that the value of Cronbach's Alpha for 9 items was found to be. 812 which is more than 0.6 indicated that 9 items used to measure economic factor that affect employment during crisis were reliable for this research. 


\begin{tabular}{ccc} 
& Table.14: Correlations analysis \\
\hline Factors & Pearson & Economic \\
\hline \multirow{2}{*}{ Employment } & Pearson Sig.(2-tailed) & $.801^{* *}$ \\
& $\mathrm{~N}$ & .000 \\
& & 84
\end{tabular}

Table (14) demonstrates the correlation analysis between economic as independent factors and employment as dependent factor. The value of Pearson correlation between economic factor and employment was $.801 * *$ this indicated that there is a significant correlation between economic factor and employment during crisis in private businesses in Kurdistan.

Table.14: Coefficients

\begin{tabular}{lccccc}
\hline \multirow{2}{*}{ Model } & \multicolumn{2}{c}{$\begin{array}{c}\text { Unstandardized } \\
\text { Coefficients }\end{array}$} & $\begin{array}{c}\text { Standardized } \\
\text { Coefficients }\end{array}$ & \multirow{2}{*}{ Sig. } \\
\cline { 2 - 5 } & $\mathrm{B}$ & Std. Error & Beta & & \\
\hline (Constant) & .104 & .109 & & .867 & .000 \\
\hline Economic & .801 & .108 & .812 & .902 & .000 \\
\hline
\end{tabular}

a. Dependent Variable: Employment

Table (14) demonstrates the coefficients test for testing the impact of economic factor on employment during crisis in private businesses in Kurdistan. The findings revealed that the $B$ value of for economic factor $=.801>0.01$, which indicated that there is a positive and significant impact of economic on and employment during crisis in private businesses in Kurdistan.

\section{CONCLUSION}

The discrete decision explore turned out to be a compelling technique for evaluating the conceivable effect of different strategy choices for enhancing the inspiration and maintenance of enrolled medical attendants and the outcomes supplemented the subjective discoveries. The researcher employed a single regression analysis to investigate the developed research hypotheses, however the findings revealed that Political factor has a positive and significant impact on employment during crisis in private businesses in Kurdistan, accordingly first research hypothesis was supported, Environmental factor has a positive and significant impact on employment during crisis in private businesses in Kurdistan, accordingly first research hypothesis was supported, Social factor has a positive and significant impact on employment during crisis in private businesses in Kurdistan, accordingly first research hypothesis was supported, Legal factor has a positive and significant impact on employment during crisis in private businesses in Kurdistan, accordingly first research hypothesis was supported, and finally Economic factor has a positive and significant impact on employment during crisis in private businesses in Kurdistan, accordingly first research hypothesis was supported. However, the results showed that the highest value was for economic factor this means that economic is strongly related to employment and has strong influence on employment during crisis in private businesses in Kurdistan. The procedure at the same time permitted evaluation of the effect of a few characteristics on business inclinations and, by expecting respondents to off exchange the points of interest and drawbacks of various sets of expectations, gave a sign of the relative significance of each trait. All in all, the enrolled attendants were quick to take an interest in the exploration and had couple of issues in understanding the system, since there were not very many situations when the prevalent alternative was not picked. It was fascinating to find that, except for the contrast between the arrangement of fundamental and predominant government lodging, all the chose ascribes were found to significantly affect business inclinations. This recommended, and in addition pay, the accessibility of assets, the ordinary workload, chances to redesign capabilities, and the arrangement of fundamental lodging (contrasted and none) were additionally imperative. The relative significance of the distinction ascribes to Kurdistan open part enlisted medical attendants, as evaluated by the proportions of coefficients, gives a valuable gauge of the viability of elective approach choices. Compensation was observed to be judged imperative, however open doors for assist instruction and the arrangement of essential lodging were additionally positioned nearly high. This investigation thinks about just a single part of the difficulties of reducing the lack of wellbeing experts. The examination constraints are recognized and a few zones for additionally look into have been recommended. Given the moderately restricted quantitative investigation to date of business inclinations of wellbeing laborers in developing countries, this examination gives an intriguing commitment to the writing. 


\section{REFERENCES}

[1] Alkhamis, A. A., \& Miraj, S. S. A. (2018). Links between employment-related factors and physical and mental health among uninsured expatriate males in Saudi Arabia. International Journal of Health Sciences, 12(1).

[2] Bedwell, C., McGowan, L., \& Lavender, D. T. (2015). Factors affecting midwives' confidence in intrapartum care: A phenomenological study. Midwifery, 31(1), 170-176.

[3] Boeckmann, I., Misra, J., \&Budig, M. J. (2014).Cultural and institutional factors shaping mothers' employment and working hours in postindustrial countries. Social Forces, 93(4), 13011333.

[4] Brewster, L., Mountain, G., Wessels, B., Kelly, C., \& Hawley, M. (2014). Factors affecting front line staff acceptance of telehealth technologies: a mixed-method systematic review. Journal of advanced nursing, 70(1), 21-33.

[5] Cadden, M., \& Arnett, P. (2015). Factors associated with employment status in individuals with multiple sclerosis. International journal of MS care, 17(6), 284291.

[6] Chen, W., Elam-Evans, L. D., Hill, H. A., \&Yankey, D. (2017). Employment and Socioeconomic Factors Associated With Children's Up-to-Date Vaccination Status. Clinical pediatrics, 56(4), 348-356.

[7] Curran, J., \& Baker, P. (2016).Factors influencing recruitment and retention of foundation doctors in geographically unpopular locations. Future Hospital Journal, 3(1), 17-20.

[8] De Goeij, M. C., Suhrcke, M., Toffolutti, V., van de Mheen, D., Schoenmakers, T. M., \&Kunst, A. E. (2015). How economic crises affect alcohol consumption and alcohol-related health problems: a realist systematic review. Social Science \& Medicine, 131, 131-146.

[9] Delfabbro, P., Winefield, H., Winefield, A., Malvaso, C., \&Plueckhahn, T. (2017). Factors Associated With Attrition in a 10-year Longitudinal Study of Young People: Implications for Studies of Employment in School Leavers. Australian Psychologist, 52(1), 41-51.

[10] Donohue, B., Plant, C. P., Barchard, K. A., \& Gillis, D. J. (2017). Examination of the extent to which employment factors are associated with reduced child maltreatment potential and drug use. Journal of child and family studies, 26(1), 168-175.

[11] Drydakis, N. (2015). The effect of unemployment on self-reported health and mental health in Greece from
2008 to 2013: a longitudinal study before and during the financial crisis. Social Science \& Medicine, 128, 43-51.

[12]Ellenkamp, J. J., Brouwers, E. P., Embregts, P. J., Joosen, M. C., \& van Weeghel, J. (2016). Work environment-related factors in obtaining and maintaining work in a competitive employment setting for employees with intellectual disabilities: A systematic review. Journal of occupational rehabilitation, 26(1), 56-69.

[13] Gandhi-Lee, E., Skaza, H., Marti, E., Schrader, P. G., \&Orgill, M. (2017).Faculty Perceptions of Student Recruitment and Retention in STEM Fields. European Journal of STEM Education, 2(1), 2.

[14] Houghton, Catherine, Maura Dowling, Pauline Meskell, Andrew Hunter, Heidi Gardner, Aislinn Conway, Shaun Treweek et al. "Factors that impact on recruitment to randomised trials in health care: a qualitative evidence synthesis." The Cochrane Library (2017).

[15] Hughes-Morley, A., Young, B., Waheed, W., Small, N., \& Bower, P. (2015). Factors affecting recruitment into depression trials: systematic review, metasynthesis and conceptual framework. Journal of affective disorders, 172, 274-290.

[16] Hughes-Morley, A., Young, B., Waheed, W., Small, N., \& Bower, P. (2015). Factors affecting recruitment into depression trials: systematic review, metasynthesis and conceptual framework. Journal of affective disorders, 172, 274-290.

[17] Lacour, J. R., \&Bourdin, M. (2015). Factors affecting the energy cost of level running at submaximal speed. European journal of applied physiology, 115(4), 651-673.

[18]Li, Q. (2015). Empirical Analysis of Factors Influencing Employment in China-Based on the Analysis of Johansen Co-integration Model and Error Correction Model. Management \& Engineering, (18), 33.

[19]Lins, K. V., Servaes, H., \& Tamayo, A. (2017). Social capital, trust, and firm performance: The value of corporate social responsibility during the financial crisis. The Journal of Finance, 72(4), 1785-1824.

[20] Manskow, U. S., Sigurdardottir, S., Røe, C., Andelic, N., Skandsen, T., Damsgård, E., ...\&Anke, A. (2015). Factors affecting caregiver burden 1 year after severe traumatic brain injury: A prospective nationwide multicenter study. The Journal of head trauma rehabilitation, 30(6), 411-423. 
[21] Nair, P. K., \&Farid, H. (2016).Effective factors for recruitment and retention in Malaysian private universities. International Journal of Management in Education, 10(4), 390-413.

[22] Oganjan, K., Lauringson, V., Kotta, J., Rostin, L., \& Martin, G. (2017). Factors affecting the recruitment of Amphibalanusimprovisus and Dreissenapolymorpha in a highly eutrophic brackish bay. Estuarine, Coastal and Shelf Science, 184, 37-45.

[23] Pavlínek, P. (2015). The impact of the 2008-2009 crisis on the automotive industry: global trends and firm-level effects in Central Europe. European Urban and Regional Studies, 22(1), 20-40.

[24] Saridakis, G., Marlow, S., \&Storey, D. J. (2014). Do different factors explain male and female selfemployment rates?.Journal of Business Venturing, 29(3), 345-362.

[25] Schnurr, P. J., \& Allen, D. G. (2015). Factors affecting algae biofilm growth and lipid production: a review. Renewable and Sustainable Energy Reviews, 52, 418-429.

[26] Schnurr, P. J., \& Allen, D. G. (2015). Factors affecting algae biofilm growth and lipid production: a review. Renewable and Sustainable Energy Reviews, 52, 418-429.

[27] Sima, A. P., Wehman, P. H., Chan, F., West, M. D., \&Leucking, R. G. (2015). An evaluation of risk factors related to employment outcomes for youth with disabilities. Career Development and Transition for Exceptional Individuals, 38(2), 89-100.

[28] Smith, S. G., Sestak, I., Forster, A., Partridge, A., Side, L., Wolf, M. S., ...\&Cuzick, J. (2015). Factors affecting uptake and adherence to breast cancer chemoprevention: a systematic review and metaanalysis. Annals of Oncology, 27(4), 575-590.

[29] Sockalingam, S., Wnuk, S., Kantarovich, K., Meaney, C., Okrainec, A., Hawa, R., \& Cassin, S. (2015). Employment outcomes one year after bariatric surgery: the role of patient and psychosocial factors. Obesity surgery, 25(3), 514-522.

[30] Yeager, V. A., \& Wisniewski, J. M. (2017).Factors That Influence the Recruitment and Retention of Nurses in Public Health Agencies. Public Health Reports, 132(5), 556-562. 